\title{
Effectiveness of Sleep Management Strategies in Reducing Insomnia among Elderly
}

\author{
*Ramaprabhu Z
}

\section{Abstract:}

Objectives: To evaluate the effectiveness of sleep management strategies in reducing insomnia among elderly. Methods: Pre experimental (one group pretest posttest) design. Results: The result showed that the overall mean was 74.77 with standard deviation of 19.32 in pretest and the overall mean was 19.33 with the standard deviation of 7.92 in posttest and there was a significant improvement in the sleep status of elderly with insomnia on the evaluation day. Conclusion: It shows that the sleep management strategy was effective.

Key words: Sleep Management strategy, Insomnia and Elderly

\section{INTRODUCTION}

Sleeping is no mean art; for its sake one must stay awake all day. The best bridge between despair and hope is a good night's sleep. Sleep is the golden chain that ties health and our bodies together. The average adult needs slightly more than eight hours of sleep a day but only $38 \%$ of Indian adults consistently get this amount of rest. 4

Insomnia is defined as difficulty initiating or maintaining sleep at least three nights/week, in addition to complaints of sleep related daytime impairment. People with insomnia tend to experience one or more of the following sleep disturbances such as difficulty falling asleep at night, waking too early in the morning, waking frequently throughout the night, sleep that is chronically non-restorative or poor.[4,9]

\section{NEED FOR THE STUDY}

According to the WHO census. (2008) prevalence rate of insomnia approximately one in 8 or $11.76 \%$ per 32 million people in India.
According to National Sleep Foundation, (2008) $20 \%$ to $40 \%$ of all adults encounter insomnia problems during a year time. More than 2 million children suffer from various sleep disorders. Almost $35 \%$ of people suffering from insomnia have a family history of insomnia. 55\% percent of all adults have problems with insomnia in their lifetime. ${ }^{3}$

\section{OBJECTIVES}

- To assess the level of insomnia among elderly.

- To evaluate the effectiveness of sleep management strategies in reducing insomnia among elderly

- To find out the association between the level of sleep and demographic variables.

\section{METHODOLOGY:}

The tool used in the study are given below

Section-A: Proforma for Demographic variables

Section-B: Modified Pittsburgh insomnia rating scale. 
Quantitative research approach was applied for the study. Pre-experimental design with One group pretest - posttest research design was used for this study. The study was conducted at psychiatry outpatient department of MelmaruvathurAdhiparasakthi Institute of Medical Sciences and Research.

The target population of the study included, both male and female above 60 years of age with insomnia, 30 elderly with insomnia were selected by convenient sampling technique. The data were analyzed by using descriptive and inferential statistics like frequency, percentage, mean, standard deviation, paired T-Test and Chi-Square test.

The study was conducted to determine the effectiveness of sleep management strategies in reducing insomnia among elderly. One group pre test - post test research design was adopted.

\section{SLEEP MANAGEMENT STRATEGIES:}

- RELAXATION THERAPY:

Yoga: Pranayama includes

NADISHODANA: which is done in a calm environment according to the following steps

Sit in any meditative posture with closed eyes, keep the spine erect. Close the right nostrils with the ring finger of the right hand and open the right nostril and exhale slowly.

$\checkmark$ After complete exhalation, again inhale through the right nostril and fill the lungs. Close the right nostril by pressing it with the right thumb.

$\checkmark$ After opening the left nostril, breathe out slowly and completely which can be done for ten to fifteen minutes.

\section{BHRAMARI PRANAYAMA:}

$\checkmark$ Which can do for ten to fifteen minutes in a calm environment. Sit in any meditative posture with closed eyes, keep the spine erect and close the both ears with both indicating finger gently so that on the pinna of the ear is pressed inside.

$\checkmark$ After a deep breath gently fold the tongue inside the mouth that should touch the soft palate and make humming bee sound which creates a slight vibration that's spreads all over the head.

\section{SHAVASANA:}

$\checkmark$ Lie on the back with the hands and legs comfortable away from the body then toes pointing outside. Finger in a semi flexed position. Keep the head in a most convenient position and close the eyes gently.

$\checkmark$ Start with a moderately deep abdominal breathing .Attend to the flow of the breath without moving the body and try to relax each and every part of the body consciously and try to diffuse all the tension of the body.

\section{SLEEP HYGIENE EDUCATION:}

Education on sleep hygiene was given for elderly includes sleep habits such as attempt to maintain a regular sleep wake cycle, avoid keeping a clock close to bed to prevent clock watching, taking warm bath.

$\checkmark$ Structuring the environment such as use of the bed room only for sleep and intimacy, create a comfortable, quiet, dark and temperature controlled environment and other sleep education about behavioral modification, positive perception of sleep. 
Percentage Distribution of Elderly with Insomnia based on Sleep Condition on Pre Test and Post Test.

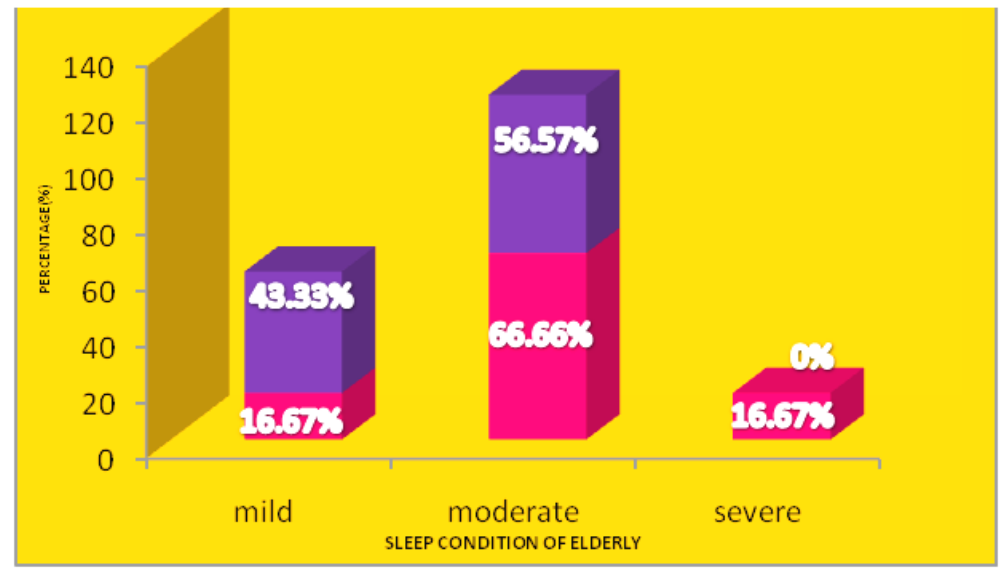

Among the 30 clients, five (16.67\%) had mild insomnia, twenty $(66.66 \%)$ had moderate insomnia, five (16.67\%) had severe insomnia during pretest. Among the 30 clients, thirteen (43.33\%) had mild insomnia, seventeen $(56.67 \%)$ had moderate insomnia duringposttest.

\section{Mean and Standard Deviation of Pre Test and Post Test Scores of Elderly with} Insomnia.

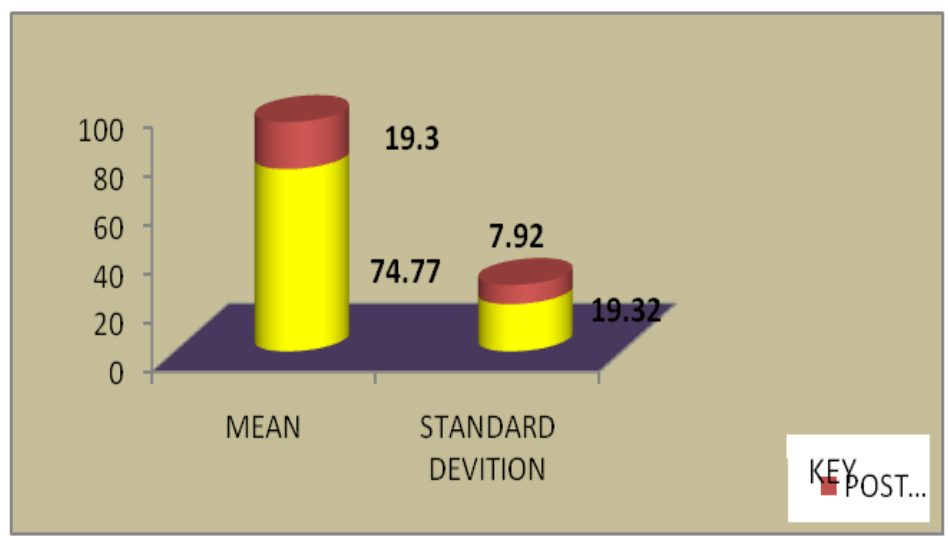

$$
\mathbf{N}=\mathbf{3 0}
$$

The overall mean was 74.77 with standard deviation of 19.32 in pretest and the overall mean was 19.33 with the standard deviation of 7.92 in posttest.

Effectiveness of Sleep Management Strategies among Elderly with Insomnia by Using Sign Test.

$$
\mathbf{N}=\mathbf{3 0}
$$

\begin{tabular}{|c|c|c|c|c|c|}
\hline S. No & Health Status & Mean & S.D & Sign test value & 'K' value \\
\hline 1 & Post test Score & 19.33 & 7.92 & 1 & 5.1 \\
\hline
\end{tabular}

${ }^{*} \mathrm{P}<0.05$ Level Significant 
The sign test value is lesser than the $\mathrm{k}$ value. This shows that there was a significant improvement in the sleep status of elderly with insomnia on the evaluation day; hence the sleep management strategies were effective.

\section{RESULTS AND DISCUSSION:}

The study was conducted to determine the effectiveness of sleep management strategies in reducing insomnia among elderly. One group pre test - post test research design was adopted.

\section{The tool used in the study are given} below Section-A: Proforma for Demographic variables Section-B: Modified Pittsburgh insomnia rating scaleThe sample includes both male and female diagnosed with insomnia. A total number of 30 samples were selected for the study. The levels of insomnia for each elderly were assessed using modified Pittsburgh insomnia rating scale.

Based on the pre test, the sleep management strategies was planned and implemented for the elderly with insomnia and effectiveness of sleep management strategies was assessed after two weeks. The study findings have been discussed in terms of the objectives of theoretical basis and hypothesis.

The first objective was to assess the level of insomnia among elderly Table reveals that frequency and percentage distribution in sleep condition of elderly with insomnia.

Among the 30 clients, five $(16.67 \%)$ had mild insomnia, twenty $(66.66 \%)$ had moderate insomnia, five $(16.67 \%)$ had severe insomnia level in pre test. Among the 30 clients, thirteen (43.33\%) had mild insomnia, seventeen $(56.67 \%)$ had moderate insomnia in post test.
The second objective was to evaluate the effectiveness of sleep management strategies in reducing insomnia among elderly. It reveals that overall mean and standard deviation of effectiveness of sleep management strategies in reducing insomnia in elderly. The overall mean was 74.77 with standard deviation of 19.32 in pre test and the overall mean was 19.3 with the standard deviation of 7.92 in post test. The improvement between pre test and post test score. The mean was 19.3 with standard deviation of 7.92. The sign test value is lesser than $\mathrm{k}$ value. This shows that there was a significant improvement in the sleep status of elderly with insomnia in post test, hence the sleep management strategies was effective.

The third objective is to correlate the effectiveness of sleep management strategies in reducing insomnia among elderly with the selected demographic variables. It shows that correlation between effectiveness of sleep management strategies in reducing insomnia among elderly with selected demographic variables.

There was no significant relation between demographic variables consists of general status such as age of elderly, sex, religion, occupational status, marital status, availability of support system, history of illness, history of medication, habits and another session sleep status such as duration of sleep per day and sleep habits with effectiveness of sleep management.

Hullar J et al., (2010) conducted study on impact of group therapeutic education in the management of adults sleep disorders in which implementation of a non pharmacological, therapeutic approach is a daily problem for primary 
insomnia conducted one month and three month after they concluded that group therapeutic education in the form of cognitive behavioral therapy performed during a conference results in a change in behaviors and a midterm improvement in sleep quality in participants.

Taylor D., (2010) studied insomnia which is a common problem that affects $9 \%-15 \%$ of the elderly population chronically. The primary objectives of this study were to demonstrate that 8 weekly session of sleep restriction therapy of insomnia combined with sleep management strategies.Reduction instruction following a single session of sleep hygiene. These results provide evidence that more intensive treatment of insomnia results in better outcomes.

These studies support the results of effectiveness of sleep management strategies in reducing insomnia among elderly. Hence it is incorporated in results and discussion.

\section{RECOMMENDATION:I}

- The study can be done in comparing with insomnia and any associated problems.

- Descriptive analysis can be done with insomnia and complication on insomnia.

- Comparative study between the various types of insomnia.

- The study can be done in large samples.

- A comparative study can be done between the rural and urban clients.

\section{REFERENCES;}

1. Ahuja.N.,"Text book of post graduate nursing"., Jaypee brothers publishers(2004) $5^{\text {th }}$ edition.,.
2. Alligard.M., "Nursing theorist and their work"., $5^{\text {th }}$ edition., Mosby company Philadelphia.(2002).

3. Ancoli-Israel S., "The impact and prevalence of chronic insomnia and other sleep disturbances associated with chronic illness"., Am J Managed Care. 2006;12:S221-9.

4. Avidan AY., "Sleep changes and disorders in the elderly patient"., CurrNeurolNeurosci Rep.2002;2:178-85.

5. Basvanthappa.B.T,"Psychiatric mental health nursing".,1 ${ }^{\text {st }}$ edition., jaypee brothers publishers(2007).

6. Bimlakapoor.," A text book of psychiatric nursing"., volume -1., Kumar publication(2003).

7. B.K.Puri., P.J.Laking.,"Text book of psychiatry"., $1^{\text {st }}$ edition ., Churchill livingstone publishers(1998).

8. Dinesh bhugra., 1st edition.," Hand book of psychiatric"., Byword viva publisher(1999).

9. Dement W, Richardson G, Prinz P, Carskadon M, Kripke O, Czeisler C., "Changes of sleep and wakefulness with age , Handbook of the Biology of Aging" .2nd ed. New York: VanNostrandReinhold;( 1996).

10.Elizabeth.M.Varcarolis.," Foundation ofPsychiatric mental health nursing"., $3^{\text {rd }}$ edition(2001). , saunder company publishers.

11.Eugene.H.Rubin., Charles. F.Zorumski.," Adult psychiatry"., $2^{\text {nd }}$ edition(2000)., Black well publisher.

12.Ford DE, Kamerow DB., "Epidemiologic study of sleep disturbances and psychiatric disorders. An opportunity for prevention". JAMA. (1989);262:147 9-84.

13.FortinashHolodayworret,"Psychiatric nursing care plans"., Mosby publishers ,(2000) $4^{\text {th }}$ edition., . 
14. Johnson EO, Roth T, Schultz L, Breslau N., "Epidemiology of DSMIV insomnia in adolescence: lifetime prevalence, chronicity, and an emergent gender difference"., Pediatrics. (2006);117:e 247-56

15. J.N.Vyas.,"Essentials of post graduate psychiatry"., paras publishers1 ${ }^{\text {st }}$ edition(2001).

16. Kaplan and Sadocks.," Concise textbook of clinical psychiatry"., $2^{\text {nd }}$ edition., Lippincott Williams and wilikins publishers.

17. Katz DA, McHorney CA., "Clinical correlates of insomnia in patients with chronic illness"., Arch Intern Med.(1998);158:1099-107

18. Mahajan.B.K.(1994)., "Methods of biostatistics"., jaypee brothers publishers.
19. MaryAnn Boyd.," psychiatric nursing contemporary practice"., $3^{\text {rd }}$ edition .,jaypee publishers.

20. Mary.C.Townsend.,"Psychiatric mental health nursing".,2nd edition., jaypee brothers publishers.

21 .McCall WV., "A psychiatric perspective on insomnia"., J Clinical Psychiatry.(2001);62(Suppl 10):2732

22. NoreenCavanFrisch.,"Psychiatric mental health nursing",,2nd edition., Delmar publisher.

23. Ohayon MM., "Prevalence of DSM-IV diagnostic criteria of insomnia: distinguishing insomnia related to mental disorders from sleep disorders"., J Psychiatr Res. (1997);31:333-46

\section{Ps of DYsPnea}

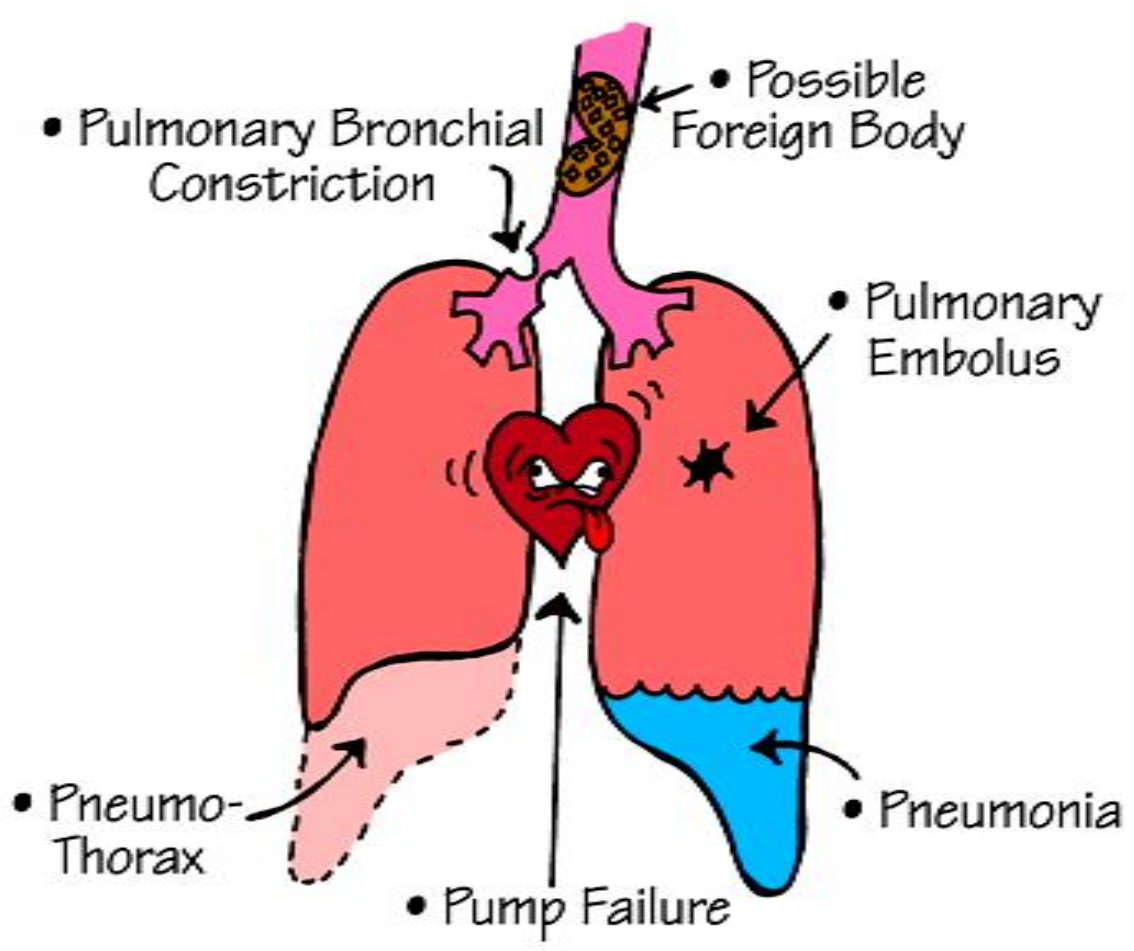

